\title{
The bending stiffness deterioration of circular steel tube considering the corrosion
}

\author{
Huajie Wang ${ }^{1, a}$, Gang Song $^{1, b}$, Hongliang Qian ${ }^{1, c}$ \\ ${ }^{1}$ School of Civil Engineering, Harbin Institute of Technology at Weihai, Weihai 264209, China \\ a huajie_wang@163.com b sgyuhuo@163.com ${ }^{\mathrm{C}}$ qianhl@hit.edu.cn
}

Keywords: Space steel structure; Atmospheric corrosion; Circular steel tube; Bending Stiffness deterioration

\begin{abstract}
The atmospheric corrosion is the main reason of behavior deterioration of space steel structure under service, especially in wet and coastal area. The circular steel tube was widely used in space steel structure, the behavior deterioration of which caused by corrosion has great influence to the structure safety. In this paper 19 kinds of circular steel tube were chosen to study based on the corrosion data of Qingdao. Based on the power function corrosion model, the corrosion simulation program and analysis of tube surface corrosion was done by ANSYS, and the rule of bending stiffness deterioration caused by corrosion with time change for 50 years was obtained, which shows that after 50 years the deterioration of thinner tube bending stiffness will exceed 10 percent, and with the wall thickness increasing, the deterioration will became not obvious.
\end{abstract}

\section{Introduction}

The development statue of large-span spatial structures is the important symbol of building technology for the country and also the sign of country and region economy power. So many large-span spatial structures were built in coastal area recent years, but because of the high humidity and chloride concentration of coastal area, the steel members were easy to corrode and the corrosion will make the behavior deteriorate, which has a great influence on the structure safety, so it is necessary to do a research on the corrosion of the steel members.

\section{The corrosion model and simulation method}

\subsection{The corrosion model}

The power function of the steel corrosion model with time change in atmospheric was widely used[1,2], and lots of atmospheric exposure test data were gleaned for many years in many countries, based on which the steel corrosion model of power function could be obtained by regression analysis as below $[3,4]$ :

$$
D=A t^{n}
$$

where $D$ is the corrosion depth in $\mathrm{mm}$; $t$ is the time in years; $A$ and $n$ are constants.

Reference[5] summarizes lots of the steel atmospheric exposure test data of China, from which the constant $\mathrm{A}$ and $\mathrm{n}$ of 7 different experimental stations were obtained as shown in the Table 1 . In this paper the test data in Qingdao were chosen to do an analysis and the corrosion model in Qingdao can be expressed as:

$$
D=0.058 t^{0.57}
$$

Table 1 Constants $A$ and $n$ in 7 experimental stations

\begin{tabular}{cccc}
\hline Place & Environment & $A(\mathrm{~mm})$ & $n$ \\
\hline Beijing & rural & 0.032 & 0.45 \\
Qingdao & marin & 0.058 & 0.57 \\
Wuhan & urban & 0.047 & 0.39 \\
Jiangjin & urban & 0.083 & 0.45 \\
Guangzhou & urban & 0.060 & 0.48 \\
\hline
\end{tabular}




\begin{tabular}{cccc}
\hline Qionghai & urban & 0.024 & 1.03 \\
Wanning & marin & 0.033 & 1.60 \\
\hline
\end{tabular}

\subsection{The method for circular steel tube corrosion simulation}

Shell 63 element of ANSYS was used to simulate the circular steel tube. And the thickness change caused by corrosion could be simulated by modifying the constant of shell 63 according to the power function of steel corrosion model. The initial finite element model was shown as Figure 1 and the local finite element model after corrosion was shown as Figure 2.

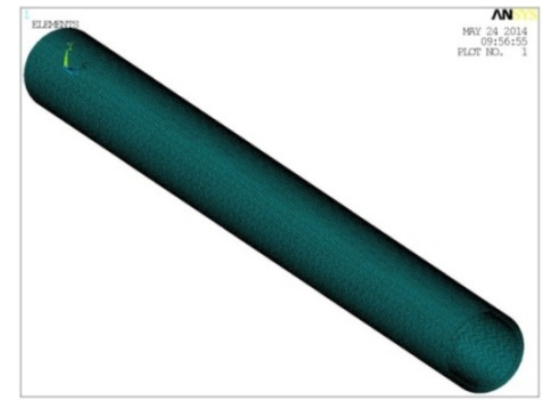

Fig.1 The circular steel tube finite element model

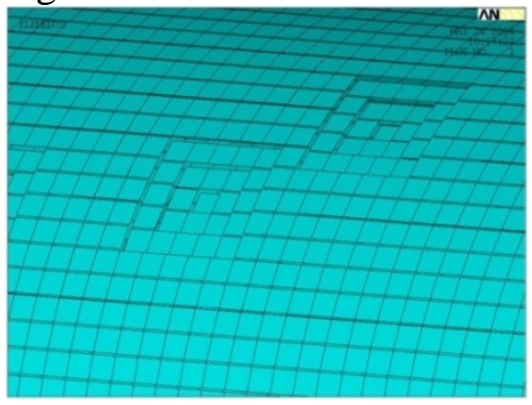

Fig. 2 The local finite element model after corrosion

First, some elements were randomly selected as initial corrosion elements and make them in a group called group 1 . Then, all the elements contact with group 1 were selected as Group 2. Just like that, except for group 1 all the elements contact with group 2 were selected as Group 3 and so on. The model was divided into many groups and each group has its own real constant. When the corrosion starts to happen, the real constant will be changed. The simulation procedure was shown as below:

(1).First year, Group 1 start to corrode and its real constant was set according to the power function corrosion model with one year $(\mathrm{t}=1)$;

(2).Second year, the real constants of group 1 was set according to the power function corrosion model with two years $(\mathrm{t}=2)$. Meanwhile, the real constants of group 2 was set with one year $(\mathrm{t}=1)$;

(3).Third year, the real constants of group 1 was set according to the power function corrosion model with three years $(\mathrm{t}=3)$ and the real constants of group 2 was set with two years $(\mathrm{t}=2)$, group 3 with one year $(\mathrm{t}=1)$, and so on.

In the paper, corrosion of 19 circular steel tubes with different diameter and thickness were simulated to make sure its bending stiffness deterioration rule.

Table 2 Circular steel tube for analysis

\begin{tabular}{cccccccccccccccccccc}
\hline Number & 1 & 2 & 3 & 4 & 5 & 6 & 7 & 8 & 9 & 1 & 1 & 1 & 1 & 1 & 1 & 1 & 1 & 1 & 1 \\
\hline $\begin{array}{c}\text { Diameter } \\
(\mathrm{mm})\end{array}$ & 76 & 89 & $\begin{array}{c}11 \\
4\end{array}$ & 140 & $\begin{array}{c}11 \\
4\end{array}$ & 140 & 159 & 140 & 159 & 180 & 140 & 159 & 180 & 159 & 180 & 219 & 180 & 219 & 245 \\
$\begin{array}{c}\text { Thicknes } \\
(\mathrm{mm})\end{array}$ & 4 & 4 & 4 & 4 & 6 & 6 & 6 & 8 & 8 & 8 & 10 & 10 & 10 & 12 & 12 & 12 & 14 & 14 & 14 \\
\hline
\end{tabular}

\section{The bending stiffness deterioration caused by corrosion}

The lengths of the members are all 2 meters and all of them are double clamped - beam with uniform load. The true bending stiffness after corroding can be obtained according to the member middle displacement during 50 years. The formula was shown as:

$$
E I=\frac{q l^{4}}{384 \Delta_{\text {mid }}}
$$

where $E I$ is the bending stiffness; $\Delta_{\text {mid }}$ is the member displacement, $q$ is the value of uniform load and $l$ is the length of the member.

2.1 The analysis of bending stiffness deterioration caused by corrosion 


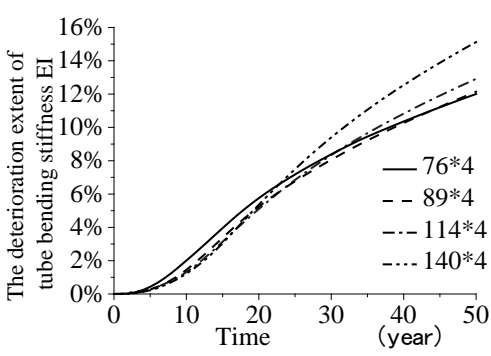

Fig. 3 The deterioration extent of tube bending stiffness

EI with $4 \mathrm{~mm}$

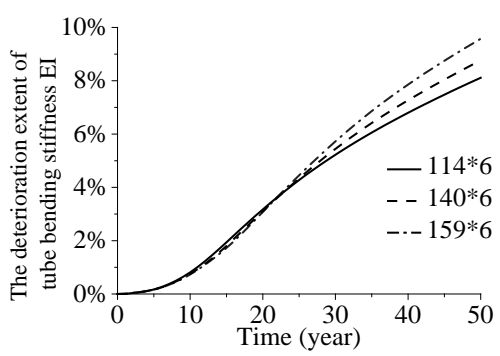

Fig. 4 The deterioration extent of tube bending stiffness EI with $6 \mathrm{~mm}$

The deterioration extent of tube bending stiffness EI with $4 \mathrm{~mm}$ thickness is between $12 \%$ and $15 \%$ in 50 years as shown in Figure 3. The deterioration extent with $6 \mathrm{~mm}$ thickness is between $8 \%$ and $10 \%$ in 50 years as shown in Figure 4.

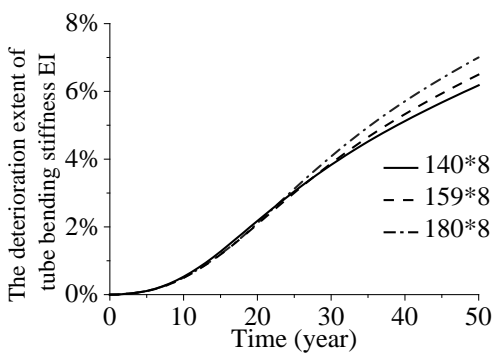

Fig. 5 The deterioration extent of tube bending stiffness

EI with $8 \mathrm{~mm}$

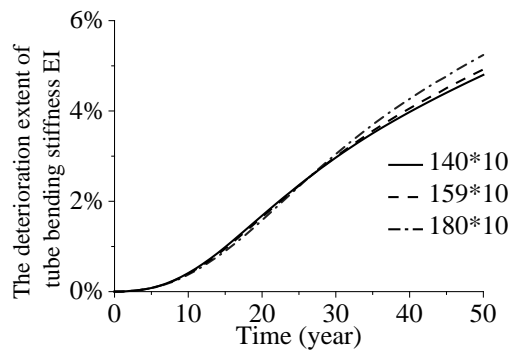

Fig. 6 The deterioration extent of tube bending stiffness EI with $10 \mathrm{~mm}$

The deterioration extent of tube bending stiffness EI with $8 \mathrm{~mm}$ thickness is between $6 \%$ and $7 \%$ in 50 years as shown in Figure 5 . The deterioration extent with $10 \mathrm{~mm}$ thickness is between $5 \%$ and $6 \%$ in 50 years as shown in Figure 6.

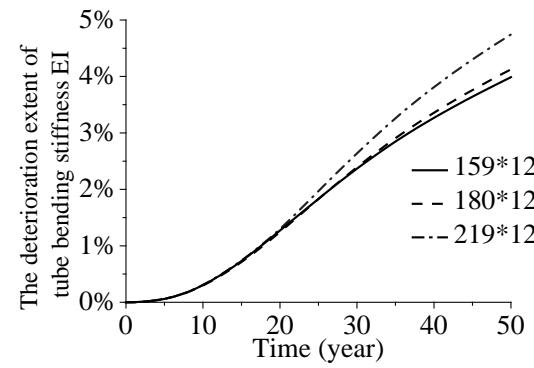

Fig. 7 The deterioration extent of tube bending stiffness

EI with $12 \mathrm{~mm}$

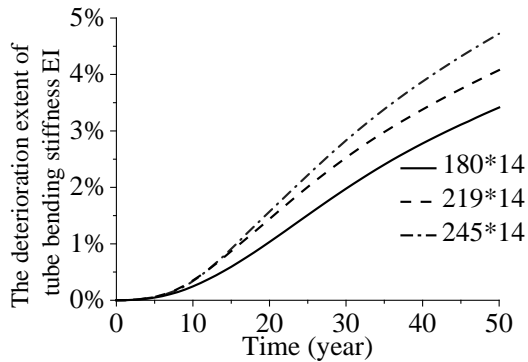

Fig. 8 The deterioration extent of tube bending stiffness EI with $14 \mathrm{~mm}$

The deterioration extent of tube bending stiffness EI with $12 \mathrm{~mm}$ thickness is between $4 \%$ and 5\% in 50 years as shown in Figure 7. The deterioration extent with $14 \mathrm{~mm}$ thickness is between 3.5\% and $4.5 \%$ in 50 years as shown in Figure 8.

\subsection{The deterioration model of the bending stiffness}

It is evident from the analysis above that the differences of deterioration extent of the tube bending stiffness with same thickness are very slight, so the deterioration extent of the tube bending stiffness mainly depend on the thickness but not the diameter, and the curves between the deterioration extent of tube bending stiffness EI and time could be obtained by averaging the deterioration data of the circular steel tubes with different diameter but same thickness, as shown in Figure 9. 


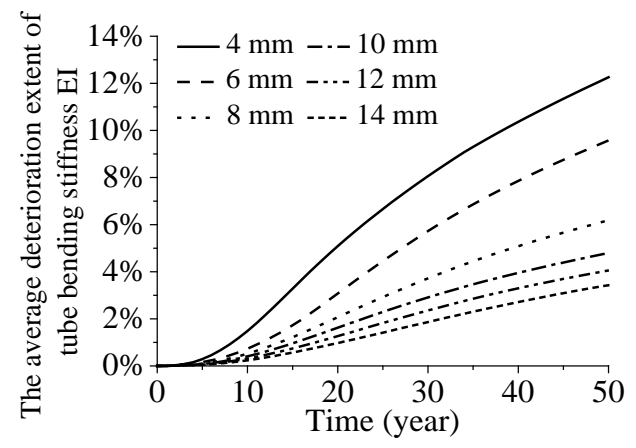

Fig. 9 The deterioration extent of tube bending stiffness $E I$ of different thickness

From all the analysis above, the result could be that the diameter has small influence on deterioration extent of the tube bending stiffness but the thickness plays an important role. Based on curve fitting, a forth order polynomial about the deterioration extent of the tube bending stiffness with time could be obtained, as shown in formula (4).

$$
y=a x^{4}+b x^{3}+c x^{2}+d x+e
$$

where $y$ is the deterioration extent of the bending stiffness, $x$ is time in years and $a, b, c$ and $d$ are constants as shown in Table 3.

Table 3 Constants $a, b, c$ and $d$

\begin{tabular}{cccccc}
\hline Thickness $(\mathrm{mm})$ & $a$ & $b$ & $c$ & $d$ & $e$ \\
\hline 4 & $5.94 \mathrm{E}-6$ & $-7.01 \mathrm{E}-4$ & $2.58 \mathrm{E}-2$ & $-2.86 \mathrm{E}-2$ & $-8.4 \mathrm{E}-2$ \\
6 & $3.51 \mathrm{E}-6$ & $-4.46 \mathrm{E}-4$ & $1.82 \mathrm{E}-2$ & $-6.81 \mathrm{E}-2$ & $7.85 \mathrm{E}-2$ \\
8 & $2.06 \mathrm{E}-6$ & $-2.79 \mathrm{E}-4$ & $1.22 \mathrm{E}-2$ & $-5.04 \mathrm{E}-2$ & $6.68 \mathrm{E}-2$ \\
10 & $1.70 \mathrm{E}-6$ & $-2.27 \mathrm{E}-4$ & $0.98 \mathrm{E}-2$ & $-4.41 \mathrm{E}-2$ & $5.38 \mathrm{E}-2$ \\
12 & $1.02 \mathrm{E}-6$ & $-1.50 \mathrm{E}-4$ & $0.71 \mathrm{E}-2$ & $-3.00 \mathrm{E}-2$ & $4.23 \mathrm{E}-2$ \\
14 & $1.105 \mathrm{E}-6$ & $-1.53 \mathrm{E}-4$ & $0.69 \mathrm{E}-2$ & $-2.93 \mathrm{E}-2$ & $3.72 \mathrm{E}-2$ \\
\hline
\end{tabular}

\section{Conclusion}

In this paper, the bending stiffness deterioration of circular steel tube were in-depth analyzed based on the corrosion data of Qingdao, and the following conclusions can be drawn:

(1).From the analysis in the paper, we can see that the deterioration extent of tube bending stiffness with $4 \mathrm{~mm}$ thickness is more than $12 \%$ after 50 years, but the deterioration extent with $14 \mathrm{~mm}$ thickness is only near 3.5\%, which means that if the thickness is bigger, the bending stiffness deterioration is smaller caused by corrosion. And the analysis also shows that with the same thickness, if the diameter is bigger the bending stiffness deterioration is higher but not obvious.

(2).Through the analysis of the tube bending stiffness deterioration caused by corrosion, a forth order polynomial of the deterioration extent of the tube bending stiffness with time was obtained by curve fitting, which could provide evidence for the prediction of the bending stiffness deterioration of circular steel tube.

\section{Acknowledgement}

This research was financially supported by the National Natural Science Foundation of China (Grant No.51378149).

\section{References}

[1] Mendoza A R, Corvo F. Outdoor and indoor atmospheric corrosion of carbon steel[J]. Corrosion Science, 1999,41(2):75 -86

[2] Yu. M. Panchenko, A.I. Marshakov. Long-term forecast of corrosion mass losses of technically important metals in various world regions using a power function[J]. Corrosion Science, 2014,

[3] M. Morcillo, B.Chico, I.Diaz. Atmospheric corrosion data of weathering steels[J]. Corrosion Science, 2013. 
[4] R.E. Melchers. Long-term corrosion of steels exposed to marine environments[J]. Eur. J. Environ. Civil Eng. 13 (5) (2009) 527-546.

[5] Cao Chunan. Material corrosion in natural environment of China[M]. Beijing: Chemical Industry Press, 2004. 